\title{
INVESTIGANDO PRINCÍPIOS DE DESIGN DE UMA SEQUÊNCIA DIDÁTICA SOBRE METABOLISMO ENERGÉTICO
}

\section{Investigating design principles of a teaching sequence about energetic metabolism}

\author{
Anna Cássia de Holanda Sarmento ${ }^{1}$. Cássia Regina Reis Muniz ${ }^{2}$. \\ Natália Rodrigues da Silva ${ }^{3}$. Valter Alves Pereira ${ }^{4}$. \\ Maria Aparecida dos Santos Santana ${ }^{5}$. Thiago Serravalle de Sá ${ }^{6}$ \\ Charbel Niño El-Hani ${ }^{7}$
}

\begin{abstract}
Resumo: Este artigo contempla uma investigação sobre princípios de design de uma sequência didática que visa favorecer a aprendizagem sobre metabolismo energético na primeira série do Ensino Médio. O estudo foi realizado por pesquisadores e professores-investigadores reunidos numa equipe colaborativa. Consideramos, na sequência, critérios de justificação a priori, relativos a aspectos epistemológicos, psicocognitivos e didáticos. Na validação a posteriori, utilizamos pré- e pós-testes, triangulando métodos quantitativos e qualitativos. Os princípios de design incluíram: uso de textos de divulgação científica, contextualização dos assuntos em relação ao cotidiano dos estudantes, processo coletivo e cooperativo de aprendizagem. A intervenção mostrou efeitos positivos dos princípios de design quanto à motivação dos estudantes e à aprendizagem de conteúdos, sobretudo sobre transformações de energia, fermentação e biotecnologia. Contudo, algumas concepções alternativas resistiram a mudanças, especialmente aquelas relativas à fotossíntese e respiração celular, fornecendo indicações para o aprimoramento dos princípios de design e de sua implementação em sala.
\end{abstract}

Palavras-chave: Ensino de ciências. Ensino Médio. Sequência didática. Metabolismo energético. Professor-investigador.

\begin{abstract}
This paper reports results of an investigation about the characteristics of a teaching sequence aiming to promote learning about energetic metabolism in the 10th grade. The study was conducted by researchers and practitioners gathered in a collaborative team. In order to elaborate the sequence, we considered a priori justification criteria relative to epistemological, psycho-cognitive and didactic aspects. A posteriori validation was performed using pre- and post-tests, triangulating qualitative and quantitative methods. The design principles included: the use of popular science texts, the contextualization of contents in relation to students' everyday life, a collective and cooperative learning process. The intervention showed positive results of the design principles regarding students' motivation and learning about contents, mostly about energy transformations, fermentation and biotechnology. However, some alternative conceptions were resistant to change, notably those regarding photosynthesis and cellular respiration, providing indications for the improvement of the design principles and their implementation in the classroom.
\end{abstract}

Keywords: Science education. High school. Teaching sequence. Energetic metabolism. Teacher-researcher.

${ }^{1-4}$ Colégio da Polícia Militar da Bahia (CPM), Avenida Dendezeiros, s/n, Bonfim, Salvador, BA, CEP 40843-040, Brasil. E-mail: anna.cassia01@hotmail.com.

${ }^{5-7}$ Universidade Federal da Bahia (UFBA), Instituto de Biologia, Laboratório de Ensino, Filosofia e História da Biologia (LEHFIBio), Salvador, BA, Brasil. 
Sarmento, A. C. H. et al.

\section{Introdução}

O ensino de ciências deve constituir um meio para ampliar a compreensão do estudante sobre a realidade, fornecendo-lhe instrumentos para orientar suas decisões e intervenções no mundo que o cerca. A importância do conhecimento científico e tecnológico para a formação dos estudantes pode ser justificada, por exemplo, a partir de sua contribuição para que estes se desenvolvam como cidadãos autônomos e críticos (SANTOS; MORTIMER, 2000), sobretudo em relação a questões sociocientíficas (SADLER, 2005, 2009; ZEIDLER; SADLER, 2005; KOLSTØ et al., 2006). Contudo, como discutido por Pedrancini et al. (2007), o ensino promovido no ambiente escolar nem sempre permite que o estudante se aproprie dos conhecimentos científicos de modo a utilizá-los como instrumentos de pensamento, extrapolando as situações escolares de ensino e aprendizagem. Dito de outra forma, o modelo de ensino predominante na Educação Básica, em geral pautado na transmissão de conhecimentos e sem esforços de contextualização destes em relação à vida cotidiana dos alunos, não tem sido eficaz para a formação de um indivíduo crítico e ativo, consciente da sua importância para a modificação da realidade em que vive e do potencial do conhecimento científico e tecnológico para tal transformação. Neste cenário, torna-se relevante investigar novas estratégias para o ensino de conteúdos da educação científica (BORGES; LIMA, 2007), em particular, buscando promover condições para que os estudantes alcancem maior domínio das linguagens científicas e de suas representações, como previsto nos PCNEM (BRASIL, 2001), assim como uma melhor compreensão da ciência e tecnologia, de seus aspectos históricosociais e de suas relações com a sociedade e o ambiente (relações CTSA).

$\mathrm{Na}$ literatura sobre ensino de ciências, encontramos argumentos a favor de situações de ensino que busquem aproximar o conhecimento científico do cotidiano e das experiências dos estudantes (KRASILCHIK, 2000), por exemplo, contextualizando os conteúdos científicos em face de questões sociocientíficas (SADLER, 2005, 2009; ZEIDLER; SADLER, 2005; KOLSTØ et al., 2006). Outros trabalhos destacam a importância de estimular atividades em grupo (BARAB et al., 2007; NELSON et al., 2005), assim como de incentivar a curiosidade e o entusiasmo naturais dos alunos pela ciência e tecnologia (CACHAPUZ; PRAIA; JORGE, 2004). Barab et al. (2007) apontam, ainda, a importância da contextualização dos conteúdos científicos de forma articulada com questões tecnológicas. Entretanto, os materiais instrucionais, incluindo os livros didáticos, não costumam apresentar estas características, raramente utilizando contextualização em relação ao cotidiano e à experiência dos estudantes ao trabalharem os conteúdos científicos, não constituindo exceções os livros didáticos de Biologia e Química (ABREU; GOMES; LOPES, 2005).

Este modo de abordar os conteúdos torna particularmente difícil trabalhar, em sala, assuntos que demandam mobilização de conceitos de mais de um campo do conhecimento e são exigentes em relação à cognição dos estudantes, como é o caso do metabolismo energético. Sintomaticamente, estudos têm apontado este assunto como um dos mais difíceis para a compreensão dos estudantes, entre aqueles abordados no ensino de Biologia (PATRO, 2008; MARMAROTI; GALANOPOULOU, 2006). Como discutido por Patro (2008), estas dificuldades também podem ser atribuídas à complexidade dos fenômenos envolvidos, que englobam grande número de reações químicas e moléculas, assim como ao vocabulário técnico utilizado, que representa uma novidade para os estudantes do Ensino Médio. Marmaroti e 
Galanopoulou (2006) apontam, por sua vez, que a dificuldade dos estudantes de compreenderem a fotossíntese está relacionada ao fato de que estes não conseguem estabelecer conexões entre os vários conteúdos da Biologia, da Química e da Física que são necessários ao entendimento dessa temática. De fato, percebemos, em nossas práticas docentes, estas mesmas dificuldades, oriundas, em especial, da forma como os conteúdos de Biologia e Química são apresentados, em disciplinas distintas, que não dialogam entre si, lado a lado com a falta de vínculos com o cotidiano do estudante.

O metabolismo energético é um tema importante na educação científica, na medida em que diz respeito a processos químicos essenciais à manutenção da vida, cuja compreensão tem papel central na capacidade do estudante de entender os sistemas vivos e seu funcionamento (VAI; BICUDO; VAI, 2005). Além disso, noções sobre metabolismo energético facilitam a compreensão de tecnologias úteis à vida humana, muitas delas presentes na vida cotidiana dos estudantes, tendo um papel relevante no desenvolvimento de habilidades e competências para lidarem consciente e criticamente consigo mesmos e com o mundo ao redor. Afinal, os fenômenos de transformação de energia relativos ao metabolismo estão presentes em diversos contextos do cotidiano: na realização de atividades físicas; na produção de alimentos; na compreensão de processos biotecnológicos para a conservação da natureza e minimização de impactos ambientais, na produção de energia limpa etc.

Diante das dificuldades de ensino e aprendizagem trazidas pelo assunto metabolismo energético e de sua relevância para a formação dos estudantes, torna-se clara a importância de se investigarem inovações didáticas no ensino deste tema. Estas inovações podem se pautar, por sua vez, em características apontadas pela literatura sobre ensino de ciências, tais como: a contextualização do conhecimento científico em relação ao cotidiano e às experiências dos estudantes, bem como a questões sociocientíficas e tecnológicas; o estímulo às atividades em grupo, ou seja, a processos coletivos e cooperativos de aprendizagem; e o incentivo à curiosidade e ao entusiasmo dos alunos pela ciência e tecnologia (BARAB et al., 2007; CACHAPUZ; PRAIA; JORGE, 2004; NELSON et al., 2005). Diante destas indicações encontradas na literatura e de nossa própria experiência docente, decidimos investigar uma sequência didática ${ }^{8}$ (SD) para o ensino de Biologia que apresentasse tais características, usando textos de divulgação científica disponíveis na mídia como meio de implementá-la em sala de aula. O uso de textos de divulgação científica pode cumprir diferentes funções, como a motivação e o estímulo à participação dos estudantes (NASCIMENTO; ALVETTI, 2006), e, também, como propomos aqui, a aproximação de conteúdos de ciências em relação a experiências cotidianas, entre as quais não podemos deixar de incluir, no contexto contemporâneo, o contato com notícias veiculadas pela mídia e com produtos consumidos na vida diária.

Relatamos, aqui, resultados de uma investigação de características de uma SD, nos moldes do design research, visando favorecer a aprendizagem sobre metabolismo energético no Ensino Médio. A design research inclui diferentes tipos de estudo, entre os quais podemos des-

\footnotetext{
${ }^{8}$ Entendemos "sequência didática", aqui, tal como proposto por Zabala (1998, p. 18): um conjunto de atividades ordenadas, estruturadas e articuladas para a realização de certos objetivos educacionais, que têm um princípio e um fim conhecidos tanto pelos professores como pelos alunos.
} 
Sarmento, A. C. H. et al.

tacar os estudos de desenvolvimento e de efetividade (NIEVEEN; MCKENNEY; VAN DEN AKKER, 2006; PLOMP, 2009). Este último tipo de estudo está focado sobre a efetividade de uma intervenção, como a própria designação indica, e, para produzir a evidência necessária à sua realização, demanda grandes estudos de campo comparativos, envolvendo números suficientes de casos - turmas em que uma SD ou outra inovação educacional é aplicada - e controles - turmas em que o mesmo assunto é abordado mediante outra proposta pedagógica. Ou seja, para chegar a uma conclusão que relacione causas (no processo de ensino) e efeitos (na aprendizagem), este tipo de estudo requer um desenho quasi-experimental de casos e controles, que permita distinguir, nos processos complexos e multifatoriais de ensino e aprendizagem, fatores causais e efeitos bem definidos. Contrariamente a uma visão dominante na comunidade de pesquisadores em educação, de que este tipo de desenho não pode ser realizado na investigação educacional a não ser que controlemos as variáveis mediante condução da pesquisa em laboratório, entendemos que este tipo de desenho pode ser implementado caso acomodemos as variáveis presentes na sala de aula que não digam respeito ao que queremos testar (as chamadas "variáveis de confusão"), a exemplo da empatia professor-aluno, do grau de motivação e envolvimento dos estudantes de diferentes turmas, do conhecimento prévio dos alunos etc. É para acomodar tais variáveis de confusão que necessitamos de números suficientes de réplicas do caso e de réplicas do controle. Se tivermos réplicas suficientes, poderemos separar os efeitos da intervenção dos efeitos de variáveis de confusão. Se não as tivermos, as conclusões de tais estudos não serão confiáveis, dada a dificuldade de separar relações de causa e efeito de outras variáveis.

Tendo em vista as condições objetivas da pesquisa situada na escola, é evidente que nem sempre dispomos de oito turmas de uma mesma série para realizar estudos focados em relações de causa e efeito. No caso do presente estudo, no entanto, havia a disponibilidade de tais turmas. A decisão de não realizar um estudo de efetividade decorreu, então, de outras razões: o grande esforço de coleta de dados para um estudo de causa e efeito pode não ser justificável enquanto não tiverem sido realizados estudos de caso visando ao próprio desenvolvimento da intervenção educacional. Por este motivo, decidimos iniciar nosso processo de pesquisa com estudos de desenvolvimento. Este tipo de estudo está focado sobre a resolução de um problema educacional, no nosso caso, as dificuldades envolvidas no ensino e na aprendizagem sobre metabolismo energético, enfatizando a natureza prática das intervenções. Os produtos esperados são princípios de design ou planejamento de intervenções didáticas amplamente aplicáveis, utilizando, para tanto, o desenvolvimento iterativo de intervenções aplicadas em variados contextos (no que se denomina "ciclos de prototipagem"), com avaliação de seus sucessos e limites através de uma comparação entre as vias de aprendizagem planejadas na intervenção e as vias de aprendizagem efetivamente realizadas em sala de aula.

Este estudo, em particular, trata da investigação de princípios de design de uma SD sobre metabolismo energético no seu primeiro ciclo de prototipagem. O estudo foi realizado no contexto de turmas da primeira série do Ensino Médio do Colégio da Polícia Militar, Unidade Dendezeiros em Salvador, BA, por um grupo ${ }^{9}$ colaborativo de: professores da Edu-

\footnotetext{
${ }^{9}$ Grupo Colaboração em Pesquisa e Prática em Educação Científica (CoPPEC). Ver Sepulveda et al. (2012). 
cação Básica, licenciandos, bacharelandos, pesquisadores acadêmicos e pós-graduandos, que foi constituído a partir da participação numa comunidade virtual de prática (ComPratica) focada no ensino de Biologia (EL-HANI; GRECA, 2009, 2011, 2013; sobre comunidades de prática, ver LAVE; WENGER, 1991; WENGER, 1998).

\section{Materiais e métodos}

\section{Aspectos metodológicos gerais}

Utilizamos, em nosso estudo, uma abordagem qualitativa, conduzida com base na design research, entendida como o estudo sistemático do planejamento, da implementação, da avaliação e da manutenção de intervenções educacionais inovadoras, visando à busca de soluções para problemas da prática educacional (BAUMGARTNER et al., 2003; PLOMP, 2009). A investigação foi conduzida no contexto real da sala de aula dos professores-investigadores envolvidos no projeto. Esta abordagem qualitativa foi triangulada com métodos quantitativos, utilizando-se critérios e procedimentos descritos a seguir.

Para a elaboração da SD, usamos critérios de justificação a priori discutidos por Artigue (1998) e Méheut (2005), como modos de tornar uma intervenção clara e apropriada ao contexto da sua aplicação. Estes critérios incluem três dimensões: 1) epistemológica, relacionada aos conteúdos a serem aprendidos, aos problemas que eles podem resolver e à sua gênese histórica; 2) psicocognitiva, relativa às características cognitivas dos estudantes relacionadas com as possibilidades de compreensão do assunto; e 3) didática, referente às restrições do funcionamento escolar (programas, cronogramas, carga horária etc.).

A investigação da SD também envolveu critérios de validação a posteriori (ARTIGUE, 1998; MÉHEUT, 2005), através de uma validação interna, realizada por meio de pré e póstestes e combinando tratamentos qualitativo e quantitativo dos dados. Como mencionado acima, trata-se de um estudo de desenvolvimento de inovação educacional, envolvendo comparação entre vias de aprendizagem planejadas e efetivamente realizadas em sala de aula, como meio de avaliar o cumprimento dos requisitos particulares que motivaram a pesquisa e a validade dos princípios de design (FREY; DYM, 2006).

O processo de pesquisa proposto pela design research envolve três fases: pesquisa preliminar, fase de prototipagem e fase avaliativa. A pesquisa preliminar busca, através de uma revisão da literatura pertinente e do saber docente, fazer uma análise dos problemas e das necessidades situadas num contexto de ensino e aprendizagem, bem como desenvolver princípios de design ou planejamento da inovação educacional. A fase de prototipagem compreende ciclos de investigações em que intervenções são construídas, testadas e aperfeiçoadas. Caso a intervenção não apresente os resultados desejados ou permita alcançá-los apenas parcialmente, pode-se afirmar que os princípios de design não conduziram ainda à aprendizagem esperada, ou, ao menos, que o modo como se decidiu implementá-los não satisfez as expectativas assumidas. Este fato conduz a novas decisões quanto ao planejamento da intervenção e, assim, a novos ciclos de testes. Contudo, mesmo que todos os objetivos de aprendizagem assumidos sejam atingidos, novos ciclos de prototipagem, ainda assim, são necessários para avaliar a possibilidade de estender a inovação a outros contextos educacionais. Afinal, a cada ciclo de 
Sarmento, A. C. H. et al.

investigação de um protótipo de inovação educacional, deve haver um aumento do número de participantes da pesquisa, ou seja, dos números de estudantes e de professores-investigadores. A terceira fase, também chamada de avaliação semissomativa, permite concluir se a intervenção, depois de várias iterações, atingiu as expectativas planejadas, inclusive em sua extensão a novos contextos, mantendo-se o interesse focado sobre as vias de aprendizagem esperadas. Esta fase também resulta em recomendações e diretrizes para o aprimoramento da intervenção.

Este estudo trata da avaliação preliminar e do desenvolvimento do primeiro protótipo de uma sequência para o ensino de metabolismo energético no Ensino Médio a partir dos princípios de design levantados. Como o presente estudo envolve a construção e o teste, apenas, do primeiro protótipo da SD, a fase de avaliação semissomativa não será discutida aqui.

Uma expectativa central da design research é a produção de generalizações transponíveis para o contexto de outras intervenções (PLOMP, 2009). Estas generalizações consistem numa compreensão teórica sobre princípios de design ou planejamento da SD (e não na SD em si mesma), bem como sobre o próprio processo de construção e investigação da intervenção educacional (SARMENTO et al., 2011). Tais generalizações podem ser pensadas em termos do que Simons et al. (2003) chamam de "generalização situada", na qual os dados relativos a um determinado contexto se tornam evidências transferíveis para outros contextos, conquanto haja conexão e similaridade visíveis entre a situação em que a pesquisa foi realizada e as situações em que outros professores trabalham, de modo que estes últimos se sintam inclinados a utilizar a compreensão que a pesquisa gerou (SARMENTO et al., 2011).

Outra perspectiva de generalização com a qual trabalhamos é a de generalização potencializada pela maximização da variedade de contextos, uma das cinco linhas de raciocínio propostas por Larsson (2009, p. 31) como parte de uma visão pluralista sobre a generalização em estudos qualitativos. Neste caso, a generalização é tornada possível pelo aumento de casos qualitativamente diferentes que compõem a base empírica, e não pela representatividade propiciada por uma amostragem extensa e randômica. Para alcançar esta outra forma de generalização, estamos realizando uma série de testes de diferentes protótipos da SD sobre metabolismo energético, em várias salas de aula de três escolas diferentes. No presente artigo, embora tratemos de um estudo conduzido em uma destas escolas, como parte da segunda fase do ciclo de pesquisa descrito acima, os resultados se mostram generalizáveis nos dois sentidos já indicados anteriormente: (i) em termos de sua generalização situada, na medida em que os princípios de design investigados podem ser utilizados por outros professores que trabalhem em condições semelhantes àquelas dos professores-investigadores que participaram da pesquisa; (ii) em termos de uma generalização decorrente da variedade de contextos, uma vez que a SD foi testada em turmas que se mostravam consideravelmente diversas (ver seção "Desenho do teste da sequência didática”).

\section{Construção da sequência didática}

A motivação para a construção da SD decorreu de um texto de divulgação científica, intitulado "Modificação genética de bactéria aumenta produção de hidrogênio" (BUENO, 2008), que foi divulgado por uma das professoras-investigadoras na ComPratica. O texto trata da modificação genética de Escherichia coli para que esta proporcione, através da fermentação, uma produção significativa de hidrogênio, passível de uso como fonte de energia. Nas discus- 
sões na ComPratica, ganhou relevância a ideia de que o metabolismo energético poderia ser discutido em sala de aula a partir deste texto, de maneira a ir além da memorização de conteúdos relativos aos processos metabólicos, criando condições para a contextualização dos mesmos em relação às experiências cotidianas dos estudantes, bem como para a discussão de questões sociocientíficas capazes de contribuir para a construção de uma postura cidadã.

Diante das expectativas geradas pela discussão na comunidade de prática, uma professora-investigadora do Ensino Médio (a primeira autora do presente artigo) produziu um protótipo preliminar da SD, que foi, então, aprimorado por meio de discussão na ComPratica, através de um fórum virtual, e no grupo colaborativo de pesquisa em reuniões presenciais. Os princípios de design incorporados à construção da SD, desde seu protótipo preliminar, foram os seguintes: (1) o uso de textos de divulgação científica para contextualizar o ensino do metabolismo energético, não sendo necessariamente o texto mencionado acima, dado que, por razões psicocognitivas e didáticas, outros textos podem mostrar-se mais adequados a contextos de ensino distintos daquele no qual foi conduzido o estudo aqui relatado. De fato, em outras escolas envolvidas no projeto, foi preciso selecionar outros textos para uso na intervenção; (2) O foco sobre a contextualização dos assuntos em relação ao cotidiano do aluno e a questões sociocientíficas relevantes para a sua formação como cidadão, dada a importância do metabolismo para a manutenção das atividades vitais dos seres vivos e seu emprego biotecnológico, que traz consigo impactos sociais e ambientais; (3) a busca pela construção de um processo coletivo e cooperativo de aprendizagem, embasado na teoria sociointeracionista de Vigotski (2001), privilegiando atividades de interação e discussão em grupos de alunos, mediadas pelo professor. Por fim, durante as discussões na ComPratica a respeito da SD, mais um princípio de design emergiu: (4) A integração interdisciplinar entre a SD sobre metabolismo energético e uma SD sobre reações químicas, implementada na disciplina de Química. Esta última SD foi construída por outra professora-investigadora - também autora do presente artigo - que, apesar de formada em Biologia, ministra aulas de Química e percebeu a oportunidade de integrar o ensino das duas disciplinas. A SD sobre reações químicas será, contudo, objeto de outro artigo.

A partir da discussão da SD sobre metabolismo energético na ComPratica, foi produzido o primeiro protótipo, cujo teste é relatado neste artigo. A abordagem dos conteúdos sobre metabolismo energético foi informada por uma reflexão contínua sobre sua dimensão epistemológica, em especial no que diz respeito às relações ciência-tecnologia-sociedade-ambiente (CTSA), que ganharam relevância no planejamento da SD, a partir dos textos de divulgação científica. Contudo, a SD também objetivou a aprendizagem de conceitos específicos do metabolismo energético, relevantes para a compreensão da importância deste tipo de metabolismo para a manutenção das atividades vitais dos seres vivos. Os textos de divulgação científica serviram tanto para a contextualização do tema, quanto para iniciar e motivar discussões acerca de questões mais específicas do metabolismo. Os princípios de design propostos para a contextualização do tema em relação ao cotidiano dos alunos e para a construção de um processo coletivo e cooperativo de aprendizagem também mereceram grande atenção na construção da SD, configurando-se como aspectos inovadores no nosso contexto de ensino, capazes de motivar e engajar os alunos no processo de aprendizagem.

O desenvolvimento psicocognitivo dos estudantes também foi levado em conta durante a construção e aplicação da SD, para que esta se mostrasse apropriada ao contexto de 
Sarmento, A. C. H. et al.

ensino em que seria aplicada. Por fim, tendo em vista a dimensão didática, o terceiro critério de justificação a priori considerado no estudo, a intervenção foi planejada para ocupar 10 horas-aula do cronograma escolar, visto que este é o tempo normalmente usado para ensinar sobre metabolismo energético na escola onde a intervenção foi realizada. Parece-nos que esta é, ademais, uma extensão de tempo realista no que diz respeito ao currículo escolar do Ensino Médio, em termos gerais.

O planejamento da SD se encontra resumido no Quadro $1 .{ }^{10}$

\section{Desenho do teste da sequência didática}

A SD foi aplicada em 13 turmas do primeiro ano do Ensino Médio do Colégio da Polícia Militar, Unidade Dendezeiros, no município de Salvador, BA, sob responsabilidade de três professores participantes da equipe de pesquisa. As turmas apresentavam comportamento heterogêneo, incluindo desde turmas agitadas e dispersas até turmas disciplinadas e quietas.

De um lado, isso torna a resposta à SD dependente do perfil da turma, mas, de outro, permite obter generalizações mais confiáveis quanto aos princípios de design utilizados, na medida em que os mesmos foram testados em turmas que eram, de fato, diversas.

As turmas investigadas totalizavam 407 estudantes, mas como excluímos aqueles que não participaram de uma ou mais etapas do estudo, a população amostral final foi de trezentos e setenta estudantes. Os pais de todos os alunos envolvidos assinaram um termo de consentimento livre e esclarecido, autorizando a participação dos mesmos no estudo. A SD teve seu início no dia 1 de outubro de 2009 e foi concluída no dia 12 de novembro do mesmo ano.

A intervenção envolveu as disciplinas de Biologia e Química, como mencionado acima. Contudo, a SD sobre reações químicas não foi aplicada a seis turmas, porque o professor responsável pelas mesmas não participou do estudo. Embora os dados apresentados digam respeito apenas à intervenção aplicada na disciplina de Biologia, não podemos ignorar que o envolvimento de apenas seis das 13 turmas na SD sobre reações químicas é uma variável que pode introduzir ruídos nos resultados.

Realizamos a coleta de dados através de diversos instrumentos de natureza qualitativa e quantitativa, a fim de triangular os resultados. Os professores-investigadores realizaram observações da sua própria prática, mediante a utilização de anotações feitas por eles em caderno de campo, relativas ao engajamento e à motivação dos alunos nas diferentes atividades da SD. Coletamos dados sobre a aprendizagem dos estudantes de três maneiras: pré-teste, produção de textos e pós-teste ${ }^{11}$. Neste estudo, não usamos os dados obtidos a partir dos textos produzidos pelos alunos, que serão objeto de outro artigo.

Antes de sua aplicação, os instrumentos foram discutidos no grupo colaborativo mencionado acima, o Grupo CoPPEC, que reúne: professores da Educação Básica, licencian-

\footnotetext{
${ }^{10}$ A sequência didática pode ser obtida em sua forma completa com os autores, ou, alternativamente, pode ser feito o download a partir do site <http://www.moodle.ufba.br/mod/forum/discuss.php?d=79023>. Acesso em: 09 ago. 2013.

${ }^{11}$ Não foi realizado teste de retenção em decorrência de limitações impostas pelo calendário da escola.
} 
Quadro 1. Planejamento semanal das atividades da sequência didática, apresentando o tempo de duração e observações a respeito das mesmas

\begin{tabular}{|c|c|c|}
\hline $\begin{array}{l}\text { Atividades } \\
\text { Primeira semana }\end{array}$ & Tempo & Observações \\
\hline $\begin{array}{l}\text { Explicação da dinâmica das } \\
\text { atividades da sequência didática }\end{array}$ & $30 \mathrm{~min}$. & $\begin{array}{l}\text { O professor esclarece todos os pontos em que há dúvidas por parte dos } \\
\text { alunos. }\end{array}$ \\
\hline $\begin{array}{l}\text { Divisão da turma em cinco } \\
\text { grupos de estudo }\end{array}$ & $20 \mathrm{~min}$. & $\begin{array}{l}\text { O professor deixa que os alunos se organizem de acordo com suas } \\
\text { afinidades. }\end{array}$ \\
\hline $\begin{array}{l}\text { Leitura em grupo do texto de } \\
\text { divulgação científica }\end{array}$ & $50 \mathrm{~min}$. & $\begin{array}{l}\text { Os alunos ficam livres para interagirem com os colegas. O professor } \\
\text { caminha entre os grupos, esclarecendo dúvidas dos alunos. }\end{array}$ \\
\hline $\begin{array}{l}\text { Discussão com toda a turma } \\
\text { sobre as ideias contidas no } \\
\text { texto e sorteio dos temas de } \\
\text { pesquisa para os grupos }\end{array}$ & $50 \mathrm{~min}$. & $\begin{array}{l}\text { Professor sistematiza as ideias dos alunos, tendo em vista suas relações } \\
\text { com o conhecimento escolar, direcionando a discussão para o assunto } \\
\text { metabolismo energético. Ao final, o professor sorteia temas para pesquisa } \\
\text { em grupo: Fotossíntese; Fermentação láctica e alcoólica; Respiração } \\
\text { Celular. Devem ser pesquisadas aplicações desses tipos de metabolismo } \\
\text { para o desenvolvimento de tecnologias visando à produção de alimentos e } \\
\text { combustíveis, considerando, ainda, os impactos ambientais e sua } \\
\text { mitigação. }\end{array}$ \\
\hline \multicolumn{3}{|l|}{ Segunda semana } \\
\hline $\begin{array}{l}\text { Aulas expositivas sobre } \\
\text { metabolismo energético }\end{array}$ & $\begin{array}{l}150 \\
\min .\end{array}$ & $\begin{array}{l}\text { Introdução de conceitos científicos sobre fermentação lática, fermentação } \\
\text { alcoólica, respiração celular e fotossíntese. São abordadas suas etapas, } \\
\text { os organismos que as realizam, as condições necessárias para a } \\
\text { ocorrência dos processos, sua finalidade, importância para os organismos } \\
\text { e aplicações biotecnológicas }\end{array}$ \\
\hline \multicolumn{3}{|l|}{ Terceira semana } \\
\hline $\begin{array}{l}\text { Leitura e discussão, em grupo, } \\
\text { do material pesquisado pelos } \\
\text { alunos e de textos selecionados } \\
\text { pelos professores }\end{array}$ & $50 \mathrm{~min}$. & $\begin{array}{l}\text { Os textos selecionados abordaram as seguintes temáticas: } \\
\text { biorremediação; produção de cachaça; aumento da produtividade de } \\
\text { alimentos, fibras, madeira e combustível e produção de oxigênio } \\
\text { atmosférico; aterros sanitários e produção de biogás; produção de iogurte } \\
\text { (outras temáticas podem ser abordadas, de acordo com o contexto } \\
\text { escolar).Nessa atividade, os alunos interagem livremente com os colegas } \\
\text { e o professor se desloca entre os grupos, esclarecendo dúvidas. }\end{array}$ \\
\hline $\begin{array}{l}\text { Dissolução dos grupos originais } \\
\text { e formação de novos grupos, } \\
\text { seguindo uma modificação da } \\
\text { técnica conhecida como Philips } \\
66 \text { (FABRA,1994) }\end{array}$ & $50 \mathrm{~min}$. & $\begin{array}{l}\text { Essa atividade tem como objetivo socializar os conhecimentos adquiridos } \\
\text { nos grupos originalmente formados, como também contribuir para a } \\
\text { consolidação do que os estudantes aprenderam, na medida em que } \\
\text { cada um deles fica encarregado de explicar os assuntos relativos aos } \\
\text { estudos do seu grupo original para os colegas oriundos dos outros grupos. } \\
\text { Este procedimento coloca os alunos na posição de sujeitos ativos do } \\
\text { processo de aprendizagem. }\end{array}$ \\
\hline $\begin{array}{l}\text { Dissolução dos grupos e } \\
\text { abertura para discussão geral, } \\
\text { com toda a turma }\end{array}$ & $50 \mathrm{~min}$. & $\begin{array}{l}\text { Todos os alunos expõem suas ideias, mas o professor conduz o processo } \\
\text { de sistematização do conhecimento científico escolar. O professor verifica } \\
\text { as ideias e os entendimentos dos alunos, bem como corrige possíveis } \\
\text { equívocos em relação à perspectiva da ciência escolar. }\end{array}$ \\
\hline \multicolumn{3}{|l|}{ Quarta semana } \\
\hline Elaboração de textos & $50 \mathrm{~min}$ & $\begin{array}{l}\text { Elaboração de dois textos sobre metabolismo energético e emprego } \\
\text { biotecnológico. No primeiro texto, os alunos escrevem livremente sobre o } \\
\text { tema. No segundo, recebem as seguintes palavras-chave, que devem usar } \\
\text { para a sua elaboração: reações químicas, transformação de energia, } \\
\text { combustão, metabolismo energético, anabolismo, catabolismo, respiração } \\
\text { celular, fermentação, fotossíntese, biotecnologia, poluição ambiental e } \\
\text { energia limpa. }\end{array}$ \\
\hline
\end{tabular}

Fonte: Elaborado pelos autores. 
dos, bacharelandos, pesquisadores acadêmicos e pós-graduandos. Esta foi a instância de validação dos instrumentos, com base numa análise crítica pormenorizada e coletiva, combinando observações oriundas tanto da experiência com a pesquisa educacional quanto do saber docente dos professores-investigadores. Em decorrência de limitações impostas pelo calendário da escola em que o estudo foi realizado, não foi possível validar os instrumentos também por meio de teste-piloto com estudantes da mesma. Não percebemos, contudo, problemas significativos durante seu uso no âmbito do próprio estudo.

Os instrumentos de coleta de dados foram integrados, na medida do possível, nas práticas dos professores, dentro dos procedimentos de avaliação, de modo a diminuir a sua carga de trabalho, já que estavam envolvidos tanto com a docência quanto com a pesquisa durante o estudo, bem como para evitar multiplicar as atividades que os estudantes deveriam realizar. Isso colocou alguns limites quanto à natureza dos instrumentos, dado que deveriam suprir, também, as demandas de avaliação da escola, mas contribuiu, ao mesmo tempo, para a viabilidade do estudo.

O pré-teste correspondeu a um questionário contendo 21 questões fechadas e cinco questões abertas, enquanto o pós-teste apresentava 23 questões fechadas e cinco abertas. Os instrumentos foram planejados de acordo com os objetivos esperados da SD e em consonância com os textos de divulgação científica e a prática dos professores. Os quadros 2 e 3 trazem exemplos de questões dos instrumentos utilizados. ${ }^{12}$ Além de questões que tratavam de conteúdos específicos sobre metabolismo energético, os pré e pós-testes também apresentavam questões relativas aos aspectos biotecnológicos. Enquanto estas últimas tinham como objetivo mensurar conhecimentos sobre as aplicações biotecnológicas do metabolismo, em conformidade com os temas abordados nos textos de divulgação científica, as primeiras pretendiam fazer o mesmo em relação aos conteúdos específicos tratados nas aulas expositivas e, também, nas discussões em grupo.

Não foram utilizadas questões repetidas no pré e pós-testes, para evitar o chamado efeito do teste, ou seja, a melhora que um sujeito pode apresentar ao responder uma questão pela segunda vez, apenas pela repetição, e não pela aprendizagem dos conteúdos. Contudo, como mostram as questões apresentadas nos quadros 2 e 3 , buscamos elaborar itens similares para os mesmos conteúdos nas duas etapas de coleta de dados, de modo a preservar a comparabilidade dos instrumentos.

As questões se relacionavam a distintos temas: armazenamento de energia (três questões no pré-teste e duas no pós-teste), biotecnologia (quatro e duas), energia de ativação (uma e uma), fermentação (três e três), fenômenos químicos (uma e nenhuma), fotossíntese (duas e quatro), metabolismo (dez e dez), reações químicas (cinco e sete), respiração (cinco e quatro). Quanto aos escores, as questões fechadas apresentavam apenas dois níveis, sendo certas ou erradas (valores 0 ou 1), enquanto as questões abertas apresentavam três níveis, podendo ser corretas, parcialmente corretas ou incorretas ( $0 ; 0,5$ ou 1$)$. Atribuímos, também, o valor 0 para as questões sem resposta. Consideramos esta decisão acertada, uma vez que, enquanto o pós-

\footnotetext{
${ }^{12}$ Os instrumentos de coleta de dados estão disponíveis em: < http://www.moodle.ufba.br/mod/forum/ discuss.php?d=79023 > . Acesso em: 09 ago. 2013.
} 
Quadro 2. Exemplos de questões aplicadas no pré-teste. As questões fechadas requeriam respostas do tipo verdadeiro ou falso

Pré-teste - questões fechadas
01- O metabolismo energético é um processo que envolve transformação de matéria e energia. ( )
02- O metabolismo energético é imprescindivel para a vida na Terra. ( )
07- A biodegradação está associada ao metabolismo das bactérias. ( )
08- O oxigênio é um fator decisivo para iniciar e manter a biodegradação do petróleo, pois a base deste
processo é a reação de combustão, da qual o oxigênio é um dos reagentes. ( )
Pré-teste - questões abertas
A fermentação é um tipo de metabolismo energético no qual há quebra parcial da glicose, em ausência
de oxigênio, com a liberação parcial da energia armazenada nas ligações químicas dessa molécula
orgânica. Ocorre no citoplasma das células em anaerobiose (ausência de oxigênio), tendo um baixo
rendimento energético (apenas duas moléculas de ATP). A fermentação lática é exemplo desse
metabolismo.
22- De que maneira o emprego tecnológico desse metabolismo energético beneficia o ser humano?
26- No século XVIII, foram feitos experimentos simples mostrando que um camundongo colocado em
um recipiente de vidro fechado morria depois de algum tempo. Posteriormente, uma planta e um
camundongo foram colocados em um recipiente de vidro, fechado e iluminado, e verificou-se que o
animal não morria.
a) Por que o camundongo morria no experimento I?
b) O que possibilitou a sobrevivência do camundongo no experimento II? Justifique sua resposta.
d) Considerando que a função respiratória é desempenhada, em diferentes níveis, pelos pulmões e por
todas as células, que relação existe entre a troca de gases que o ratinho realiza com o ambiente e a
degradação da glicose que suas células realizam?

Fonte: Elaborado pelos autores.

teste fez parte da avaliação regular da disciplina, correspondendo a uma das notas da unidade, a participação no pré-teste foi voluntária e facultativa, contando apenas com aqueles alunos motivados e engajados no processo de pesquisa ${ }^{13}$. A partir dos escores de cada questão, foram calculados, para cada instrumento, os escores globais de cada aluno, que representam o seu percentual de acertos.

Para testar o efeito da SD, utilizamos um teste T para dados emparelhados, a fim de verificar a diferença entre os escores globais do pré- e do pós-teste. Os dados respeitaram os critérios de normalidade (Shapiro-Wilk, $\mathrm{p}=0,0708$ ) e homogeneidade da variância (Levene, $\mathrm{p}=0,062)$, requeridos pelo teste utilizado. A normalidade dos dados foi verificada através do programa $\mathrm{R}^{\circledR}$. Para a homogeneidade da variância e o teste $\mathrm{T}$, utilizamos o programa $S P S S^{\circledR}$ for Windows, version 14.

\footnotetext{
${ }^{13}$ A diferença entre o pré-teste, voluntário e facultativo, e o pós-teste, integrado na avaliação regular da disciplina, pode sem dúvida ter influenciado nos resultados obtidos. Note-se, contudo, que foram usados, no pós-teste, somente os dados de estudantes que haviam feito voluntariamente o pré-teste, o que implica estarmos centrando nossa análise sobre os estudantes mais motivados e engajados. Se, de um lado, isso pode significar que os avanços conseguidos entre pós-teste e pré-teste dependem do engajamento produtivo dos estudantes, de outro, esse desenho metodológico torna ainda mais relevantes os dados sobre suas dificuldades persistentes (ver abaixo). Além disso, a motivação e o engajamento são pré-condições esperadas da aprendizagem bem-sucedida, não sendo espúrio conduzir uma investigação com tais pré-condições satisfeitas.
} 
Sarmento, A. C. H. et al.

Quadro 3. Exemplos de questões do pós-teste. As questões fechadas requeriam respostas do tipo verdadeiro ou falso. (O asterisco * corresponde ao texto das questões 6-12 do pós-teste)

Pós-teste - questões fechadas
01- O metabolismo energético é de vital importância para os seres vivos. ( )
03- O metabolismo energético nem sempre envolve transformação de energia. ( )
07- Os processos anaeróbico e aeróbico citados no texto* são, respectivamente, a fermentação e a
respiração celular. ( )
09-A poluição do ambiente aquático por esgoto reduz os níveis de oxigênio na água, o que limita o
processo de respiração celular, afetando todos os seres vivos do ecossistema. ( )
12- No processo aeróbico, o oxigênio é um dos reagentes, por isso é necessário um grande suprimento
desse gás. ( )

Pós-teste - questões abertas

A fermentação é um tipo de metabolismo energético no qual há quebra parcial da glicose, em ausência de oxigênio, com a liberação parcial da energia armazenada nas ligações químicas dessa molécula orgânica. Ocorre no citoplasma das células em anaerobiose (ausência de oxigênio), tendo um baixo rendimento energético (apenas duas moléculas de ATP). A fermentação lática é exemplo desse metabolismo.

25- Comente sobre o aproveitamento do metabolismo dos microrganismos para o desenvolvimento de biotecnologias úteis para o homem.

28- Dois grupos de ratos A e B foram colocados em câmaras de vidro transparente. No grupo A, cada câmara continha uma planta verde, separada por uma tela. No grupo B, cada câmara não continha a planta verde.

As câmaras foram, então, hermeticamente fechadas e colocadas em ambiente iluminado. Após algum tempo, os ratos de um dos grupos morreram, enquanto os ratos do outro grupo resistiram por mais tempo.

a) Qual dos dois grupos de ratos sobreviveu por mais tempo?

b) Qual a explicação para esse fato?

d) A respiração pulmonar baseia-se essencialmente no transporte de oxigênio do ar ambiental para as células e no transporte do gás carbônico das células para a atmosfera. A respiração celular corresponde à quebra da glicose, no interior da célula, com o consumo de oxigênio e liberação de gás carbônico, água e energia. Diante de tais informações, determine a relação existente entre respiração pulmonar e respiração celular nos ratinhos.

Fonte: Elaborado pelos autores.

\section{Resultados e discussão}

\section{Pré-teste}

Os resultados das questões fechadas do pré-teste mostraram que a maioria dos alunos já compreendia, previamente, o conceito de metabolismo e reconhecia o metabolismo como imprescindível à vida. Eles também reconheciam que parte da energia da glicose é usada pela célula e que a temperatura influencia na velocidade das reações. Eles não tinham conhecimento, contudo, das relações entre ligações e energia química. Concordamos com Carlsson (2002) que isso decorre da dificuldade dos alunos de compreenderem o conceito de transformação de energia. Isso pode ser atribuído à necessidade de um conhecimento mais profundo de Química, como afirmam Wirzbicki e Zanon (2009). Além disso, os alunos não correlacionaram, no pré-teste, fermentação e ausência de $\mathrm{O}_{2}$. Brandão e Corazza (2008) obtiveram os mesmos resultados e, também, perceberam que os alunos não conseguem fazer relação entre a presença deste gás e a morte de bactérias anaeróbias. 
Nas questões abertas do pré-teste, foi possível perceber que os alunos reconheciam a fotossíntese como tendo importância para a manutenção da vida apenas pela produção de oxigênio. Os alunos não conseguiam identificar os reagentes e os produtos da fotossíntese, dificuldade também detectada por Barker e Carr (1989). A grande maioria dos alunos acreditava que, durante a fotossíntese, a planta produz $\mathrm{O}_{2}$ a partir do $\mathrm{CO}_{2}$. Essa concepção alternativa também foi encontrada por Kose (2008), Seymour e Longden (1991) e Zago et al. (2007). Alguns alunos acreditavam que a fotossíntese representava a respiração da planta, que inspiraria $\mathrm{CO}_{2}$ e expiraria $\mathrm{O}_{2}$. Esse equívoco em relação à fotossíntese também foi identificado em estudos de Kose (2008), Marmaroti e Galanopoulou (2006), Souza e Almeida (2002), Stavy, Eisen e Yaakobi (1987) e Zago et al. (2007).

No pré-teste, os estudantes também não mostraram conhecer, de uma maneira geral, aplicações tecnológicas da fermentação. Isso é provavelmente decorrente do fato de os alunos, durante o Ensino Fundamental, em geral, não receberem instrução formal sobre fermentação, seja lática, acética ou alcoólica. Os resultados obtidos também indicaram a dificuldade dos alunos de relacionar os conteúdos, como mostra, por exemplo, sua dificuldade em perceber a interdependência entre respiração pulmonar e respiração celular, como também foi encontrado por Acedo e Ferrara Júnior (2008) e Boo (2007).

\section{Intervenção}

Os dados de observação coletados pelos professores em seus cadernos de campo tornaram possível uma caracterização geral da intervenção. De modo geral, a estratégia utilizada na intervenção foi muito bem recebida pelos alunos e os sinais de satisfação por um trabalho diferenciado em relação àquele usualmente realizado ficaram evidentes logo no primeiro momento de apresentação da proposta de atividades. Na primeira semana da intervenção, quando teve início a leitura e discussão do texto, os alunos se mostraram agitados, mas, em termos gerais, a atividade transcorreu com tranquilidade. As discussões foram interessantes e bastante produtivas, com a participação da maioria dos alunos. Durante as discussões, entre os assuntos abordados, podemos destacar: (1) Manipulação de bactérias para produzir Hidrogênio; (2) Hidrogênio como fonte alternativa de energia e, em particular, de energia limpa; (3) Os benefícios, para o ambiente, do uso de fontes variadas de carbono (como dejetos de indústrias) para produção de Hidrogênio; (4) O uso do açúcar pelas bactérias para obtenção de energia; (5) A natureza e o processo da pesquisa científica.

$\mathrm{Na}$ segunda semana, durante as aulas expositivas, os alunos se mostraram mais atentos às aulas e mais participativos do que de costume. Nesse momento, prevaleceu o discurso do professor, na tentativa de sistematizar os conteúdos tratados na atividade anterior e desenvolver a estória científica ${ }^{14}$.

\footnotetext{
${ }^{14}$ Utilizamos a expressão "estória científica” aqui conforme seu uso por Mortimer e Scott (2003, p. 18) para designar a perspectiva da ciência, como tornada acessível para os estudantes no espaço social da sala de aula. Estes autores derivam essa expressão, por sua vez, de Ogborn et al. (1996), que consideram que a ciência escolar oferece uma abordagem dos fenômenos naturais que se expressa em termos de ideias e convenções próprias da linguagem desta ciência, de modo a compor uma espécie de roteiro, semelhante a uma estória.
} 
Nessas aulas, abordamos conteúdos específicos sobre fermentação lática, fermentação alcoólica, respiração celular e fotossíntese, como, por exemplo, suas etapas, os organismos que as realizam, as condições necessárias para a ocorrência dos processos, sua importância para os organismos e suas aplicações biotecnológicas. Também foram discutidas as concepções alternativas que encontramos nas respostas abertas do pré-teste. O primeiro protótipo da $\mathrm{SD}$ não previa o tratamento das concepções alternativas como um princípio de design, de forma que não foram elaborados instrumentos específicos para o levantamento das mesmas. Essas concepções apareceram na análise das questões abertas do pré-teste e todas estavam relacionadas a conteúdos específicos do metabolismo energético. Não observamos no préteste, nem durante a aplicação das atividades da SD, concepções prévias acerca dos demais conteúdos presentes nos textos de divulgação científica. Diante da presença de concepções alternativas no pré-teste, adaptamos as aulas expositivas para incluir discussões que possibilitassem promover mudanças das concepções alternativas relativas ao metabolismo energético. Para tanto, fizemos uma abordagem direta, comparando estas concepções que os alunos traziam com os conceitos aceitos na ciência escolar, de modo a criar possibilidades para que pudessem reconhecer as aproximações e diferenças entre suas concepções prévias e o conhecimento científico escolar.

$\mathrm{Na}$ terceira semana, após alguma agitação inicial, a leitura dos textos selecionados transcorreu sem percalços. Em algumas turmas, tidas como desinteressadas pelo Conselho de Classe, houve dificuldades, tornando-se necessário modificar a dinâmica, de modo a dar-lhes mais tempo para pesquisa e discussão. Após a leitura e discussão do material pesquisado, novos grupos foram formados de acordo com a técnica Phillips 66 (FABRA, 1994), ou seja, os novos grupos foram constituídos por integrantes de todos os grupos anteriores, cada um sendo responsável por apresentar o trabalho feito nestes últimos para os componentes do novo grupo. Não nos ativemos, contudo, ao tempo de seis minutos previsto pela técnica para as discussões. Esta dinâmica se mostrou bem eficaz, com os alunos motivados para as exposições orais para os colegas. Alguns alunos se sobressaíram em relação a outros, em virtude de uma maior facilidade de comunicação e argumentação. Assim como discutido por Andrade e Carvalho (2002), Pinheiro, Silveira e Bazzo (2007), Quse e De Longh (2005) e Santos (2007), notamos que a introdução das relações CTSA na sequência didática possibilitou a contextualização do tema, promovendo a motivação dos alunos e facilitando a aprendizagem, bem como ampliando suas capacidades de se expressarem criticamente diante de situações do cotidiano.

Ao final das atividades, quando os grupos foram dissolvidos para a discussão geral, baseada nos argumentos utilizados pelos alunos durante o debate anterior, percebemos que estes compreenderam os fenômenos relativos ao metabolismo energético, sua importância para os organismos e suas aplicações tecnológicas. Em parte, isso parece ter decorrido, como comenta Krasilchik (2004), do fato de que os conceitos foram apresentados através de discussões contextualizadas, que se mostraram mais inteligíveis e motivadoras para a aprendizagem, bem como desafiaram a imaginação e a compreensão dos estudantes. Observamos que, nesta atividade, o perfil de turmas antes inquietas e desinteressadas se modificou para turmas participativas, tendo ocorrido, ainda, o aparecimento de lideranças espontâneas nos grupos. Este é um ponto importante a ser discutido, porque observamos que a SD possibilitou a mobilização da grande maioria dos alunos durantes as atividades, o que não era visto nos anos anteriores, quando usávamos uma abordagem mais tradicional, com foco apenas nos conteúdos específi- 
cos do metabolismo energético. Acreditamos que, no nosso contexto de ensino, a abordagem inovadora, com a utilização de textos de divulgação científica, atividades colaborativas de construção de conhecimento e contextualização em relação ao cotidiano do aluno, possibilitou uma aprendizagem mais significativa.

O uso de textos de divulgação científica auxiliou na inserção de temas contemporâneos no ensino sobre o metabolismo energético, trazendo conteúdos que não somente levavam à discussão de assuntos atuais, como, também, se conectavam com a vida cotidiana dos alunos (NASCIMENTO; ALVETTI, 2006). Pareceu-nos também que os textos facilitaram a transposição, pelos estudantes, dos conteúdos aprendidos para novos contextos (MELO; HOSOUME, 2003). De fato, percebemos que os conteúdos sobre metabolismo energético trabalhados nas aulas expositivas foram mobilizados para a reflexão e discussão dos textos, inclusive com conexões com as experiências dos alunos.

Durante a etapa de discussão geral dos textos, quando do aparecimento das concepções alternativas sobre fotossíntese, utilizamos a mesma estratégia desenvolvida nas aulas expositivas, a fim de propiciar condições para a comparação entre estas concepções e o conhecimento científico escolar e, assim, potencializar sua transformação.

$\mathrm{Na}$ quarta semana, durante a elaboração dos textos, percebemos certa insegurança dos alunos em relação à redação. No entanto, a atividade transcorreu bem, em termos gerais. Uma análise preliminar dos textos mostrou a dificuldade que os alunos apresentavam para mobilizar seus conhecimentos por meio da linguagem escrita. Uma análise detalhada desses textos será objeto de outro trabalho.

\section{Pós-teste}

No pós-teste, a análise das questões fechadas e abertas mostrou que a sequência didática contribuiu para que os alunos lograssem compreender que o metabolismo envolve transformações de energia e a relação entre ligações e energia química. Além disso, os alunos passaram a diferenciar corretamente os processos anaeróbios e aeróbios, identificando os primeiros como correspondentes à fermentação, e os segundos, à respiração. Boa parte dos alunos compreendeu o emprego biotecnológico da fermentação, quando confrontados, no pósteste, com uma situação-problema que requeria que associassem o metabolismo dos microrganismos à produção do álcool. O sucesso na aprendizagem dos estudantes pode ser relacionado ao contato com tais conteúdos nas aulas expositivas, nos textos de divulgação científica e nos textos obtidos na pesquisa em grupos, que propiciaram condições para a compreensão dos assuntos mencionados acima, provavelmente em virtude da motivação e do engajamento dos estudantes, e da contextualização em relação às suas experiências.

Os resultados do pós-teste também mostraram que, mesmo após a intervenção didática, os alunos ainda sentiam dificuldades com relação à identificação dos reagentes e produtos da fotossíntese. Além disso, também não mostraram compreender que o gás oxigênio é obtido a partir da hidrólise da água, numa das etapas da fotossíntese. Apesar de o universo de alunos que apresentava a ideia de fotossíntese como sendo o processo de respiração das plantas ter diminuído, ainda encontramos a persistência dessa concepção alternativa em alguns alunos. É importante considerar que as concepções prévias relacionadas à fotossíntese, à respiração e às trocas gasosas, desenvolvidas pelas crianças nos contextos de sua vida cotidiana, 
Sarmento, A. C. H. et al.

antes da instrução formal, são altamente resistentes a mudanças (YIP, 1998). Amir e Tamir (1990) também evidenciaram a persistência de concepções alternativas sobre a fotossíntese, tais como as que observamos. Concordamos com estes autores que a compreensão das concepções da ciência escolar a este respeito somente é possível por abordagens instrucionais que levem em consideração estas ideias preexistentes. Os princípios de design usados para a construção do primeiro protótipo da sequência não enfocaram as concepções alternativas dos estudantes, mas nossos resultados indicam que este é um princípio a ser levado em consideração em protótipos subsequentes.

De acordo com Cañal (1999), a ideia de que a fotossíntese seria a respiração das plantas está relacionada a uma comparação com o modelo de respiração mecânica (pulmonar) que é realizada pelos animais. Uma vez que os movimentos respiratórios das plantas não são visíveis, os alunos tenderiam a reduzir a sua respiração à troca de gases que é realizada na fotossíntese. Outro importante fator que influencia esta concepção alternativa é a forma como a fotossíntese é geralmente abordada, sem considerar o que foi ensinado anteriormente, tratando-a como um processo de trocas gasosas, sem enfatizar a glicose como seu principal produto ou insistindo na comparação entre fotossíntese e respiração, o que pode levar, mais uma vez, a entendê-la como um processo de trocas gasosas. Este autor defende que a mudança na forma de apresentar o conceito de fotossíntese pode reduzir os índices de permanência da concepção alternativa de que a fotossíntese seria a respiração das plantas. Yenilmez e Tekkaya (2006) também observaram a permanência de concepções alternativas relacionadas à fotossíntese e à respiração das plantas. Estes autores sugerem o uso de estratégias que combinem textos que visem promover a mudança conceitual lado a lado com discussões, buscando reduzir a permanência destas concepções.

Os resultados também mostraram que muitos alunos continuaram não conseguindo estabelecer relação entre respiração pulmonar e respiração celular. A concepção de que a respiração está relacionada apenas às trocas gasosas está provavelmente relacionada à dificuldade de compreenderem a respiração celular como um fenômeno distinto, ainda que intimamente relacionado à respiração pulmonar (SEYMOUR; LONGDEN, 1991).

Foi possível perceber, de modo geral, que os estudantes tinham, ao final da intervenção, conhecimento dos conceitos científicos, mas não conseguiam relacioná-los de modo substantivo, dando respostas evasivas quando questionados sobre as relações entre conceitos, como, por exemplo, os de respiração celular e pulmonar. As respostas a tais questões reforçam, ainda, a percepção de que os alunos apresentam dificuldade de mobilizar conhecimentos para fazer relações entre níveis diferentes de organização dos seres vivos, neste caso, entre sistemas orgânicos e células. Luís (2004) chama a atenção para a necessidade da utilização de estratégias que levem em consideração as concepções prévias dos alunos sobre respiração e sistema respiratório, buscando reestruturá-las.

\section{Comparação entre pré- e pós-teste}

O engajamento dos alunos nas atividades da sequência se refletiu em uma melhora nos seus escores no pós-teste, em relação ao pré-teste (Figura 1). Além do aumento na média, há uma maior dispersão dos escores no pós-teste, com um ganho bastante perceptível para escores mais elevados. A interpretação de que os alunos avançaram na compreensão dos con- 
teúdos relacionados ao metabolismo energético foi corroborada pelo teste $\mathrm{T}$ para dados emparelhados $(p<0,000)$, que mostrou haver um efeito significativo da sequência sobre a aprendizagem dos conteúdos. Podemos afirmar, assim, que a sequência foi, em seu primeiro protótipo, bem-sucedida, sendo necessário, contudo, discutir as mudanças mostradas pelos estudantes em relação a cada conteúdo, de modo a identificar, de maneira mais clara e precisa, pontos em que a sequência porventura necessite de aprimoramento. Esta discussão foi iniciada na seção anterior, mas, agora, é preciso considerar as médias do pré- e do pós-teste para cada tema trabalhado nas questões (Tabela 1). De um modo geral, os alunos apresentaram incremento dos escores das questões fechadas entre os testes, com exceção dos conteúdos relativos à respiração. No caso dos conteúdos concernentes a fenômenos químicos, não foi possível fazer comparações, na medida em que não foram abordados em questões do pós-teste. Quando havia questões em ambos os testes, o mesmo foi observado no caso das questões abertas, com exceção, novamente, da respiração.

O princípio de design referente ao uso de textos de divulgação científica é corroborado pelos resultados obtidos, inclusive através dos cadernos de campo dos professores, que mostram que os alunos, durante as discussões do texto trabalhado no início da sequência, conseguiram perceber a importância do uso de biotecnologias para a produção de energia limpa, bem como seu potencial de minimizar impactos ambientais e sociais decorrentes do emprego de combustíveis fósseis. Numa das turmas, uma aluna comentou, por exemplo, que o uso de dejetos de indústrias para a produção de hidrogênio a partir da fermentação diminuiria o impacto ambiental, por não demandar o desmatamento de grandes áreas para plantar cana-deaçúcar para a produção de combustíveis. Outro estudante comentou que, desse modo, seria possível evitar, também, o empobrecimento do solo provocado pelas grandes plantações. Um terceiro aluno observou que o uso do Hidrogênio também diminuiria a incidência de doenças, porque não acarretaria a emissão de substâncias nocivas à saúde. Estes exemplos são corroborados pelos escores obtidos no pré e pós-teste no caso das questões relativas à biotecnologia (Tabela 1).

Ao comparar as questões abertas do pré e do pós-teste, nota-se que a diferença entre as respostas dos estudantes, nestes dois momentos, foi menor do que no caso das questões fechadas. Isso pode ser decorrente, em nosso entendimento, do fato de os alunos não estarem preparados para responder questões desse tipo, uma vez que, na escola onde aplicamos a sequência, prevalecem avaliações com questões fechadas. Como discute Vigotski (2001), a motivação para o ato de escrever se encontra distante das necessidades imediatas da criança, além de a linguagem escrita ter uma dificuldade inerente, por ser mais abstrata, exigindo um trabalho mais consciente de estruturação do significado. Isso mostra outro ponto a ser aprimorado na sequência, relativo à necessidade de se trabalhar mais a linguagem escrita durante a mesma.

Na Tabela 1, percebemos, também, que o conceito que apresentou uma maior mudança conceitual foi o de fermentação. Esta mudança provavelmente ocorreu em decorrência do uso dos textos de divulgação científica e, sobretudo, por causa da contextualização através da produção biotecnológica de iogurte e de cachaça, temas que fazem parte do cotidiano dos alunos. Durante as aulas, foi notório quanto os alunos se interessaram por aprender sobre estes temas e se surpreenderam ao saber que a produção de alguns alimentos dependia do metabolismo dos microrganismos. 
Sarmento, A. C. H. et al.

Figura 1. Escores dos estudantes no pré-teste e no pós-teste. O diâmetro dos círculos corresponde ao número de estudantes superpostos, com os mesmos escores, conforme a escala à direita do gráfico.

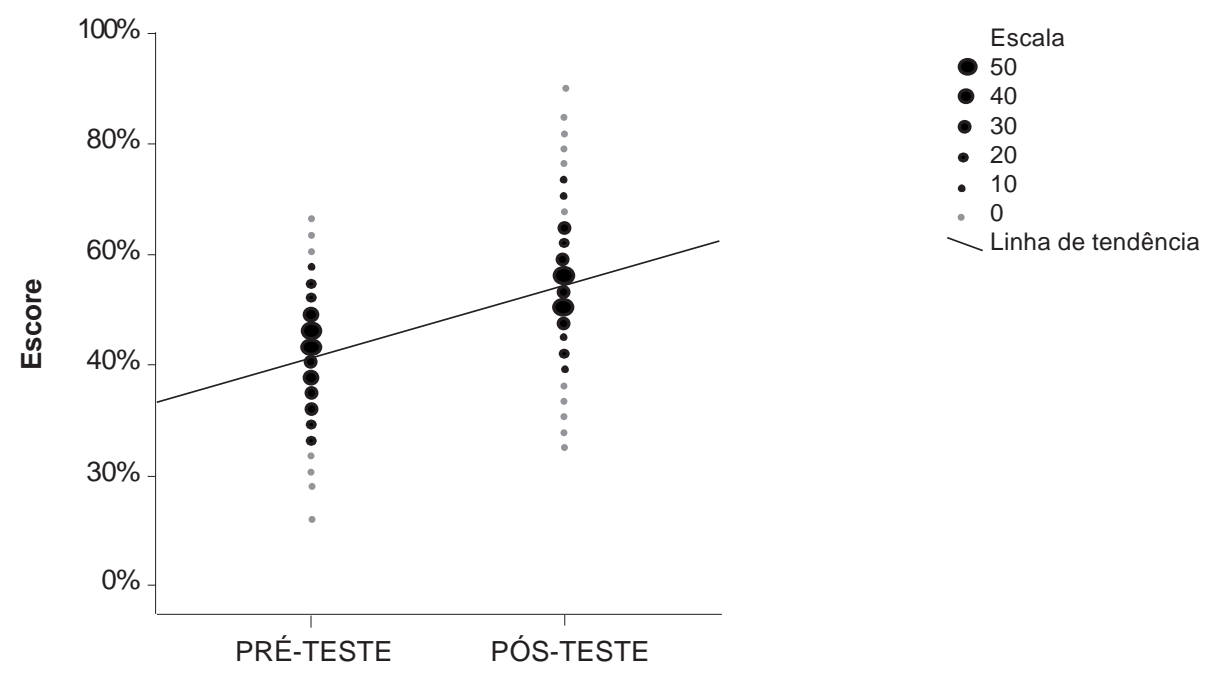

Fonte: elaborado pelos autores a partir de dados do estudo realizado.

Tabela 1. Médias dos escores das questões fechadas e abertas do pré- e do pós-teste quando separadas por assunto. $\mathrm{O}$ traço (-) corresponde à ausência de questões sobre aquele assunto.

\begin{tabular}{lcccc}
\hline & $\begin{array}{c}\text { Pré-teste } \\
\text { questões } \\
\text { fechadas (\%) }\end{array}$ & $\begin{array}{c}\text { Pós-teste - } \\
\text { questões } \\
\text { fechadas (\%) }\end{array}$ & $\begin{array}{c}\text { Pré-teste - } \\
\text { questões } \\
\text { abertas (\%) }\end{array}$ & $\begin{array}{c}\text { Pós-teste- } \\
\text { questões } \\
\text { abertas (\%) }\end{array}$ \\
\hline Armazenamento de energia & 30,47 & 52,02 & 12,43 & - \\
Biotecnologia & 31,56 & 45,94 & 2,57 & 27,57 \\
Energia de ativação & 70,27 & 81,35 & - & - \\
Fermentação & 16,16 & 52,52 & 5,07 & 30,95 \\
Fotossíntese & 39,05 & 68,14 & 39,05 & 67,91 \\
Fenômenos químicos & 24,59 & - & - & - \\
Aspectos gerais do metabolismo & 61,93 & 69,16 & 43,65 & 45,61 \\
Respiração celular & 48,76 & 34,79 & 31,28 & 8,65 \\
Reações químicas & 18,47 & 36,45 & 4,77 & 16,15 \\
\hline
\end{tabular}

Fonte: elaborado pelos autores a partir de dados do estudo.

De forma contrária, os dados da Tabela 1 mostram que houve uma redução dos escores nas questões sobre respiração celular. Acreditamos que isso decorreu do fato de ter sido dada ênfase, durante as atividades da sequência, a aspectos da respiração celular em microrganismos, devido ao tratamento dos processos biotecnológicos. Contudo, o pós-teste apresentou questões que tratavam da respiração ao nível das células de organismos pluricelulares. Acreditamos que essa mudança gerou certa confusão nos alunos, que não conseguiram 
fazer a transposição do conhecimento de um nível a outro, o que mostra dificuldade dos estudantes quanto à aplicação do conhecimento adquirido em novas situações.

O Quadro 4 traz exemplos de respostas dos alunos no pré e no pós-teste. Para a construção do quadro, foram usadas respostas de um mesmo aluno nas duas coletas de dados. Este quadro traz exemplos relacionados aos pontos discutidos acima, quanto: à permanência de concepções alternativas, à aprendizagem sobre a aplicação biotecnológica do metabolismo dos microrganismos (como exemplo de evolução da compreensão dos estudantes) e à dificuldade de relacionar respiração pulmonar, ao nível de sistemas orgânicos, e respiração celular, ao nível das células.

\section{Considerações finais}

O presente estudo permitiu mostrar o sucesso - em termos de sua validação interna - de uma SD sobre o metabolismo energético na promoção da aprendizagem dos estudantes, como mostra a diferença estatisticamente significativa entre os escores do pré e do pós-teste. Além de proporcionar aprendizagem sobre o metabolismo, a SD mobilizou visivelmente a maioria dos alunos em sala de aula no que tange à motivação, ao interesse e à participação nas atividades didáticas, como mostram os dados coletados pelos professores-investigadores em seus cadernos de campo. A inserção dos alunos nas discussões, fazendo com que atuassem como sujeitos ativos, tanto do seu processo de aprendizagem quanto do de seus colegas, transformou salas apáticas em ambientes ricos em interações. Esse fato, por si só, já é suficiente para a satisfação profissional de professores que acreditam na inovação educacional.

Os seguintes princípios de design, definidos no início da construção do primeiro protótipo da SD, foram apoiados pelos resultados do presente estudo: (1) o uso de textos de divulgação científica para contextualizar o ensino do metabolismo energético e, assim, motivar os estudantes para a aprendizagem, bem como fornecer-lhes bases para a compreensão do conteúdo a partir de suas próprias experiências; (2) a contextualização dos assuntos em relação ao cotidiano dos alunos, considerando a importância do metabolismo para a manutenção das atividades vitais dos seres vivos e seu emprego biotecnológico, bem como viabilizando um posicionamento crítico em relação a questões sociocientíficas relevantes para sua formação como cidadãos, concernentes aos impactos sociais e ambientais de tais tecnologias; (3) a construção de um processo coletivo e cooperativo de aprendizagem, privilegiando atividades de interação e discussão entre os alunos.

Os resultados do presente estudo não permitem, contudo, chegar a conclusões a respeito do quarto princípio de design, definido na discussão da SD na comunidade de prática, a saber, a integração interdisciplinar com uma SD sobre reações químicas, implementada na disciplina de Química. Para tanto, será preciso tratar conjuntamente os dados coletados com as aplicações das SDs sobre metabolismo energético e reações químicas.

Contudo, algumas considerações devem ser feitas no sentido de aprimorar a SD, visando uma nova iteração dos estudos para seu teste e desenvolvimento. Percebemos que, mesmo após a intervenção, algumas concepções alternativas persistiram nas respostas dos alunos, notadamente sobre fotossíntese e respiração celular. Será preciso, então, dedicar mais esforço ao levantamento, à discussão e à sistematização destas concepções alternativas em sala 
Sarmento, A. C. H. et al.

Quadro 4. Exemplos de respostas dos alunos no pré- e no pós-teste. Os alunos são identificados por números (A1, A2 etc.), gênero (fem. e masc.) e turma (para as quais usamos letras, A, B, C etc., após T.) de modo a manter a confidencialidade

\begin{tabular}{|c|c|c|c|}
\hline \multicolumn{4}{|c|}{ Concepções alternativas resistentes a mudanças } \\
\hline & Assuntos & Pré-Teste & Pós-Teste \\
\hline 1 & $\begin{array}{l}\text { Importância da } \\
\text { fotossíntese }\end{array}$ & $\begin{array}{l}\text { "Responsável pela produção de oxigênio." } \\
\left(A_{1} \text {, fem., T.A.). }\right. \\
\text { "É importante porque produz o oxigênio } \\
\text { utilizado na respiração celular." ( } A_{2} \text {, fem., } \\
\text { T.A.) }\end{array}$ & $\begin{array}{l}\text { "A fotossíntese é importante por causa da produção do } \\
\text { oxigênio." ( } A_{1} \text {, fem., T.A.) } \\
\text { "Produzir oxigênio." }\left(A_{2} \text {, fem., T.A.) }\right.\end{array}$ \\
\hline 2 & $\begin{array}{l}\text { Produção do } \\
\text { oxigênio }\end{array}$ & $\begin{array}{l}\text { "A fotossíntese transforma } \mathrm{CO}_{2} \text { em } \mathrm{O}_{2} \text { que é } \\
\text { muito importante para os seres vivos." ( } \mathrm{A}_{3} \text {, } \\
\text { masc., T.A.) } \\
\text { "O gás oxigênio é produzido através da } \\
\text { fotossíntese das plantas nisso a planta } \\
\text { transforma o gás carbônico em oxigênio." ( } \mathrm{A}_{4} \\
\text { masc., T.A.) }\end{array}$ & $\begin{array}{l}\text { "CO } \mathrm{CO}_{2} \rightarrow \mathrm{C}+\mathrm{O}_{2}(\ldots) \mathrm{O} \mathrm{CO}_{2} \text { existente na atmosfera é } \\
\text { absorvido pela planta que utiliza a energia solar para } \\
\text { transformar } \mathrm{CO}_{2} \text { em } \mathrm{O}_{2} . "\left(\mathrm{~A}_{3} \text {, masc., T.A.) }\right. \\
\text { "A importância é que com a fotossíntese as plantas } \\
\text { utilizam o gás carbônico e transformam em oxigênio." } \\
\left(\mathrm{A}_{4} \text {, masc., T.A.) }\right.\end{array}$ \\
\hline 3 & $\begin{array}{l}\text { Fotossíntese = } \\
\text { respiração da } \\
\text { planta }\end{array}$ & $\begin{array}{l}\text { "(..) A planta inspira } \mathrm{CO}_{2} \text { e libera } \mathrm{O}_{2}, 0 \\
\text { camundongo faz o processo inverso." }\left(\mathrm{A}_{5} \text {, }\right. \\
\text { fem., T.E.) } \\
\text { "O camundongo inspira oxigênio e expira gás } \\
\text { carbônico e a planta faz o contrário, por isso } \\
\text { o camundongo ficou vivo." }\left(\mathrm{A}_{6}, \text { masc., T.C. }\right)\end{array}$ & $\begin{array}{l}\text { "Pois o rato respira oxigênio e libera gás carbônico e a } \\
\text { planta ao contrário, havendo assim troca de } \\
\text { substâncias." }\left(A_{5} \text {, fem., T.E.) }\right. \\
\text { "O rato inspira } \mathrm{O}_{2} \text { e expira } \mathrm{CO}_{2} \text { e a planta faz o } \\
\text { contrário." }\left(\mathrm{A}_{6}, \text { masc., T.C.) }\right.\end{array}$ \\
\hline 4 & $\begin{array}{l}\text { Identificação } \\
\text { dos reagentes } \\
\text { e produtos da } \\
\text { fotossíntese }\end{array}$ & 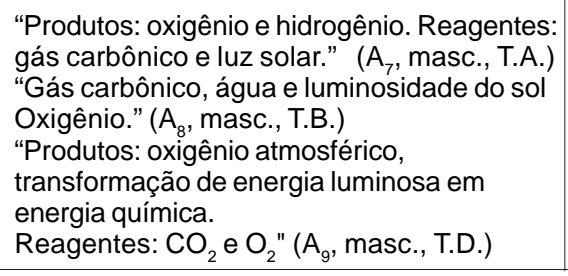 & $\begin{array}{l}\text { " } \mathrm{C}_{6} \mathrm{H}_{12} \mathrm{O}_{6}+\mathrm{O}_{2} \rightarrow \mathrm{H}_{12} \mathrm{CO}_{6}+\mathrm{H}_{2} \mathrm{O} \text { " (A, masc., T.A.) } \\
\text { " } \mathrm{H}_{2} \mathrm{O} \text { e } \mathrm{CO}_{2} \rightarrow \text { LUZ SOLAR FOTOSsíNTESE } \rightarrow \\
\text { glícidios } \rightarrow \mathrm{O}_{2} \text { " }\left(\mathrm{A}_{8} \text {, masc., T.B. }\right) \\
\left.\text { " } \mathrm{C}_{6} \mathrm{H}_{12} \mathrm{O}_{6} \rightarrow \mathrm{H}_{2} \mathrm{O}+\mathrm{CO}_{2}+\mathrm{O}_{2} \text { " (A, masc., T.D. }\right)\end{array}$ \\
\hline & & \multicolumn{2}{|c|}{ Avanços na compreensão dos estudantes } \\
\hline 5 & $\begin{array}{l}\text { Fermentação/ } \\
\text { Biotecnologia }\end{array}$ & $\begin{array}{l}\text { "A vantagem é de não ser necessário o } \\
\text { oxigênio permite que, na atmosfera, exista } \\
\text { mais oxigênio disponível para o homem." } \\
\left(\mathrm{A}_{10} \text {, fem., T.A.) }\right. \\
\text { "Nas reações que ocorrem dentro do } \\
\text { organismo como a digestão por exemplo." } \\
\left(\mathrm{A}_{11}, \text { fem., T.A. }\right)\end{array}$ & $\begin{array}{l}\text { "Com auxílio das bactérias, por exemplo, o homem } \\
\text { consegue obter a fermentação do leite e como produto, } \\
\text { a produção do iogurte. (...) As bactérias também } \\
\text { produzem o álcool, que é utilizado em larga escala } \\
\text { pelo homem." ( } A_{10} \text {, fem., T.A.) } \\
\text { "Os microrganismos, ajudam de diversas formas na } \\
\text { biotecnologia. Eles usam por exemplo o petróleo que } \\
\text { cai no mar, como fonte de energia e } \\
\text { consequentemente ajuda na limpeza de um lugar } \\
\text { poluído." }\left(\mathrm{A}_{11} \text {, fem., T.A.) }\right.\end{array}$ \\
\hline & & \multicolumn{2}{|c|}{ Dificuldades de relacionar conteúdos } \\
\hline 6 & $\begin{array}{l}\text { Respiração } \\
\text { celulare } \\
\text { respiração } \\
\text { pulmonar }\end{array}$ & $\begin{array}{l}\text { "Com a troca de gases com o ambiente, o } \\
\text { ratinho libera gás carbônico e absorve } \\
\text { oxigênio. Com a degradação da glicose, } \\
\text { ocorre a liberação de oxigênio para o corpo." } \\
\left(A_{12} \text {, masc., T.C.) }\right. \\
\text { Não respondeu. }\left(A_{13}, \text { fem., T.C.) }\right.\end{array}$ & $\begin{array}{l}\text { "Em ambos os casos há quebra da glicose (ela se } \\
\text { oxida por causa do oxigênio que atua como agente } \\
\text { oxidante) com consumo de oxigênio." ( } A_{12} \text {, masc., } \\
\text { T.C.) } \\
\text { "Respiração pulmonar } \rightarrow \text { transporte do oxigênio do ar } \\
\text { ambiental para as células e do transporte de gás } \\
\text { carbônico das células para a atmosfera } \\
\text { Respiração celular } \rightarrow \text { quebra da glicose no interior da } \\
\text { célula" }\left(\mathrm{A}_{13} \text {, fem., T.C.) }\right.\end{array}$ \\
\hline
\end{tabular}

Fonte: elaborado pelos autores a partir de dados do estudo. 
de aula. Este se configura, então, como um quinto princípio de design para os próximos protótipos da SD, que emergiu dos resultados obtidos no teste empírico do primeiro protótipo. Um sexto princípio, que também emergiu neste teste, diz respeito à necessidade de se trabalhar mais a linguagem escrita durante a $\mathrm{SD}$, dado o menor sucesso dos estudantes nas questões abertas em relação às questões fechadas presentes nos instrumentos de coleta de dados.

Diante dos resultados coletados na aplicação e no teste deste primeiro protótipo de uma SD sobre metabolismo energético, esperamos que os princípios de planejamento usados em sua construção possam ser empregados por professores em outros contextos de ensino, para a construção de outras SDs que não precisam, necessariamente, espelhar a SD que construímos, mesmo que compartilhem seus princípios de design. Assim, os dados coletados sobre o uso de tais princípios nos contextos deste estudo, em 13 turmas do Ensino Médio de uma escola pública do estado da Bahia, poderão ser transformados em evidências transferíveis para outros contextos, numa generalização teórica e situada, caso outros professores notem semelhanças com suas situações de ensino, considerando as variáveis contextuais compartilhadas.

\section{Agradecimentos}

Os autores agradecem aos árbitros de Ciência \& Educação, por suas importantes contribuições, que permitiram o incremento da qualidade do trabalho; aos participantes da ComPratica e ao grupo "Colaboração em pesquisa e prática em educação científica" (CoPPEC), por todo o apoio e pelas discussões férteis sobre o trabalho de inovação e pesquisa aqui relatado; à SEC/IAT e à FAPESB, pelo apoio concedido via Edital de Apoio à Pesquisa com Foco em Inovações Educacionais (Proj. no PET0005/2009), incluindo bolsas de professor-investigador para A.C.H.S., C.R.R.M., N.RS., e bolsa de iniciação científica para M.A.G.S.; e ao CNPQ, por bolsa de produtividade em pesquisa 1-C concedida a C.N.E. (n 301259/2010-0).

\section{Referências}

ABREU, R. G.; GOMES, M. M.; LOPES, A. C. Contextualização e tecnologias em livros didáticos de biologia e química. Investigações em Ensino de Ciências, Porto Alegre, v. 10, n. 3, p. 405-417, 2005.

ACEDO, P. H.; FERRARA JÚNIOR, N. F. Concepções de alunos de ensino médio sobre a respiração humana. ENCONTRO DE PESQUISA EM ENSINO DE FÍSICA, 11., 2008, Curitiba. Anais... Curitiba: SBF, 2008.

AMIR, R.; TAMIR, P. Detailed analysis of misconceptions as a basis for developing remedial instruction: The case of photosynthesis. ANNUAL MEETING OF THE AMERICAN EDUCATIONAL RESEARCH ASSOCIATION, 1990, Boston.

Proceedings... Boston: American Educational Research Association, 1990. p. 1-18. 
Sarmento, A. C. H. et al.

ANDRADE, E. C. P.; CARVALHO, L. M. O pro-álcool e algumas relações CTS concebidas por alunos de $6^{a}$ série do ensino fundamental. Ciência $\boldsymbol{\&}$ Educação, Bauru, v. 8 , n. 2 , p. 167-185, 2002.

ARTIGUE, M. Ingéniérie didactique. Recherches en Didactique des Mathemátiques, Grenoble, v. 9, n. 3, p. 281-308, 1988.

BARAB, S. A. et al. Relating narrative, inquiry, and inscriptions: supporting consequential play. Journal of Science Education and Technology, Dordrecht, v. 16, n. 1, p. 59-82, 2007.

BARKER, M.; CARR, M. Teaching and learning about photosynthesis. Part 1: An assessment in terms of students' prior knowledge. International Journal of Science Education, London, v. 11, n. 1, p. 49-56, 1989.

BAUMGARTNER, E. et al. Design-based research: an emerging paradigm for educational inquiry. Educational Researcher, Washington,v. 32, n. 1, p. 5-8, 2003.

BOO, H. K. Primary science assessment item setters' misconceptions concerning biological science concepts. Asia-Pacific Forum on Science Learning and Teaching, Hong Kong, v. 8, n. $1,2007$.

BORGES, R. M. R.; LIMA, V. M. R. Tendências contemporâneas do ensino de Biologia no Brasil. Revista Electrónica de Enseñanza de las Ciencias, Vigo, v. 6, n. 1, p. 165-175, 2007.

BRANDÃO, L.; CORAZZA, M. J. Produção de Wiki: uma ferramenta pedagógica para o desenvolvimento do pensamento conceitual dos estudantes do ensino médio, 2008. Disponível em: <www.diaadiaeducacao.pr.gov.br/portals/pde/arquivos/281-4.pdf>. Acesso em: 24 nov. 2009.

BRASIL. Ministério da Educação, Secretaria de Educação Média e Tecnológica.

Parâmetros curriculares nacionais: ensino médio. Brasília, 2001.

BUENO, C. Modificação genética de bactéria aumenta produção de hidrogênio. ComCiência: Revista Eletrônica de Jornalismo Científico, 24 mar. 2008. Disponível em: $<$ http:/ / www. comciencia.br/comciencia/?section=3\&noticia=418>. Acesso em: 03 out. 2009 .

CACHAPUZ, A.; PRAIA, J.; JORGE, M. Da educação em ciência às orientações para o ensino das ciências: um repensar epistemológico. Ciência \& Educação, Bauru, v. 10, n. 3, p. 363-381, 2004.

CAÑAL, P. Photosynthesis and 'inverse respiration' in plants: an inevitable misconception? International Journal of Science Education, London, v. 21, n. 4, p. 363-371,1999.

CARLSSON, B. Ecological understanding 1: ways of experiencing photosynthesis. International Journal of Science Education, London, v. 24, n. 7, p. 681-699, 2002.

EL-HANI, C. N.; GRECA, I. Uma comunidade virtual de prática como meio de diminuir a lacuna pesquisa-prática na educação científica. In: ENCONTRO NACIONAL DE 
Investigando princípios de design ...

PESQUISA EM EDUCAÇÃO EM CIÊNCIAS, 7., 2009, Florianópolis. Atas... Belo Horizonte: ABRAPEC, 2009. p. 1-13.

EL-HANI, C. N.; GRECA, I. M. Participação em uma comunidade virtual de prática desenhada como meio de diminuir a lacuna pesquisa-prática na educação em biologia. Ciência e Educação, Bauru, v. 17, n. 3, p. 579-601, 2011.

ComPratica: a virtual community of practice for promoting biology teachers' professional development in Brazil. Research in Science Education, Dordrecht, v. 43, n. 4, p. 1327-1359, 2013.

FABRA, M. L. Técnicas de grupo para la cooperación. Barcelona: Ediciones Ceac, 1994.

FREY, D. D.; DYM C. L. Validation of design methods: lessons from medicine. Research in Engineering Design, London, v. 17, n. 1, p. 45-57, 2006.

KOLSTØ, S. D. et al. Science students' critical examination of scientific information related to socio-scientific issues. Science Education, Salem, v. 90, n. 4, p. 632-655, 2006.

KOSE, S. Diagnosing student misconceptions: using drawings as a research method. World Applied Sciences Journal, Deira, v. 3, n. 2, p. 283-293, 2008.

KRASILCHIK, M. Reformas e realidade: o caso do ensino de ciências. São Paulo em Perspectiva, São Paulo, v. 14, n. 1, p. 85-93, 2000.

Prática no ensino de biologia. 4. ed. São Paulo: EDUSP, 2004.

LARSSON, S. A pluralist view of generalization in qualitative research. International Journal of Research \& Method in Education, London, v. 32, n. 1, p. 25-38, 2009.

LAVE, J.; WENGER, E. Situated learning: legitimate peripheral participation. Cambridge: Cambridge University Press, 1991.

LUÍS, N. M. L. Concepções dos alunos sobre respiração e sistema respiratório: um estudo sobre a sua evolução em alunos do ensino básico. 2004. 155 f. Dissertação (Mestrado em Educação) - Instituto de Educação e Psicologia, Universidade do Minho, Braga, 2004.

MARMAROTI, P.; GALANOPOULOU, D. Pupils' understanding of photosynthesis: a questionnaire for the simultaneous assessment of all aspects. International Journal of Science Education, London, v. 28, n. 4, p. 383-403, 2006.

MÉHEUT, M. Teaching-learning sequences tools for learning and/or research. In: BOERSMA, K. et al. (Ed.). Research and the quality of science education. Dordrecht: Springer, 2005. p. 195-207.

MELO, W. C.; HOSOUME, Y. O jornal em sala de aula: uma proposta de utilização. In: SIMPÓSIO NACIONAL DE ENSINO DE FÍSICA, 15., 2003, Curitiba. Anais... Curitiba: SBF, 2003. p. 235-611. 
Sarmento, A. C. H. et al.

MORTIMER, E. F; SCOTT, P.H. Meaning making in secondary science classrooms. Maidenhead: Open University Press, 2003.

NASCIMENTO, T. G.; ALVETTI, M. A. S. Temas científicos contemporâneos no Ensino de Biologia e Física. Ciência \& Ensino, Campinas, v. 1, n. 1, p. 29-39, 2006.

NELSON, B. et al. Design-based research strategies for developing a scientific inquiry curriculum in a multi-user virtual environment. Educational Technology, Englewood, v. 45 , n. 1, p. 21-27, 2005.

NIEVEEN, N.; MCKENNEY, S.; VAN DEN AKKER, J. Educational design research: the value of variety. In: VAN DEN AKKER, J. et al. (Ed.). Educational design research. London: Routledge, 2006. p. 151-158.

OGBORN, J. et al. Explaining science in the classroom. Buckingham: Open University Press, 1996.

PATRO, E. T. Teaching aerobic cell respiration using the 5 Es. The American Biology Teacher, Reston, v. 70, n. 2, p. 85-87, 2008.

PEDRANCINI, V. D. et al. Ensino e aprendizagem de Biologia no ensino médio e a apropriação do saber científico e biotecnológico. Revista Electrónica de Enseñanza de las Ciencias, Vigo, v. 6, n. 2, p. 299-309, 2007.

PINHEIRO, N. A. M.; SILVEIRA R. M. C. F.; BAZZO, W. A. Ciência, tecnologia e sociedade: a relevância do enfoque CTS para o contexto do ensino médio. Ciência $\boldsymbol{\&}$ Educação, Bauru, v. 13, n. 1, p. 71-84, 2007.

PLOMP, T. Educational design research: an introduction. In: PLOMP, T.; NIEVEEN, N. (Ed.). An introduction to educational design research. Enschede: Netherlands Institute for Curriculum Development, 2009. p. 9-35.

QUSE, L.; DE LONGH, A. L. ¿Qué dicen los docentes de biología del nivel medio sobre la educación CTS?: diagnóstico en Córdoba, Argentina. Revista Electrónica de Enseñanza de las Ciencias, Vigo, v. 4, n. 2, p. 1-14, 2005.

SADLER, T. D. Evolutionary theory as a guide to socioscientific decision-making. Journal of Biological Education, New York, v. 39, n. 2, p. 68-72, 2005.

Situated learning in science education: socio-scientific issues as contexts for practice. Studies in Science Education, Leeds, v. 45, n. 1, p. 1-42, 2009.

SANTOS, W. L. P. Contextualização no ensino de ciências por meio de temas CTS em uma perspectiva crítica. Ciência \& Ensino, Campinas, v. 1, p. 1-12, 2007. (Número especial).

SANTOS, W. L. P.; MORTIMER, E. F. Uma análise de pressupostos teóricos da abordagem C-T-S (Ciência-Tecnologia-Sociedade) no contexto da educação brasileira. Ensaio: pesquisa em educação em ciências, Belo Horizonte, v. 2, n. 2, p. 1-23, 2000. 
Investigando princípios de design ...

SARMENTO, A. C. H. et al. Investigando princípios de design de uma sequência didática para o ensino sobre metabolismo energético. In: ENCONTRO NACIONAL DE PESQUISA EM EDUCAÇÃO EM CIÊNCIAS, 7., 2011, Campinas. Atas... Campinas: ABRAPEC, 2011.

SEPULVEDA, C. A. S. et al. Inovando o ensino de biologia através do trabalho colaborativo de pesquisadores educacionais e professores-investigadores. Estudos IAT, Salvador, v. 2, n. 1, p. 119-137, 2012.

SEYMOUR , J.; LONGDEN, B. Respiration - that's breathing isn't it? Journal of Biological Education, New York, v. 25, n. 3, p. 177-183, 1991.

SIMONS, H. et al. From evidence-based practice to practice-based evidence: the idea of situated generalization. Research Papers in Education, London, v. 18, n. 4, p. 347-364, 2003.

SOUZA, S. C.; ALMEIDA, M. J. P. M. A fotossíntese no ensino fundamental: compreendendo as interpretações dos alunos. Ciência \& Educação, Bauru, v. 8, n. 1, p. 97-111, 2002.

STAVY, R.; EISEN, Y.; YAAKOBI, D. How students aged 13-15 understand photosynthesis. International Journal of Science Education, London, v. 9, n. 1, p. 105-115, 1987.

VAI, V. M. F. A.; BICUDO, J. E.; VAI, A. L. Metabolismo. In: EL-HANI, C. N.; VIDEIRA, A. A. P. (Org.). O que é vida?: para entender a biologia do século XXI. Rio de Janeiro: Relume Dumará, 2005. p. 105-138.

VIGOTSKI, L. S. A construção do pensamento e da linguagem. São Paulo: Martins Fontes, 2001

WENGER, E. Communities of practice: learning, meaning, and identity. Cambridge: Cambridge University Press, 1998.

WIRZBICKI, S. M.; ZANON, L. B. A complexidade de processos de significação conceitual de energia num espaço de formação para o ensino de ciências. In: ENCONTRO NACIONAL DE PESQUISA EM EDUCAÇÃO EM CIÊNCIAS, 7., 2009, Florianópolis. Atas... Belo Horizonte: ABRAPEC, 2009.

YENILMEZ, A.; TEKKAYA, C. Enhancing students' understanding of photosynthesis and respiration in plant through conceptual change approach. Journal of Science Education and Technology, Dordrecht, v. 15, n. 1, p. 81-87, 2006.

YIP, D.-Y. Identification of misconceptions in novice biology teachers and remedial strategies for improving biology learning. International Journal of Science Education, London, v. 20, n. 4, p. 461-477, 1998.

ZABALA, A. A. Prática educativa: como ensinar. Porto Alegre: Artmed, 1998. 
Sarmento, A. C. H. et al.

ZAGO, L. M. et al. Fotossíntese: concepções dos alunos do ensino médio de Itumbiara-GO e Buriti Alegre-GO. Revista Brasileira de Biociências, Porto Alegre, v. 5, p. 780-782, 2007. (Suplemento 1).

ZEIDLER, D. L.; SADLER, T. S. Beyond STS: a research-based framework for socioscientific issues education. Science Education, London, v. 89, n. 3, p. 357-377, 2005.

Artigo recebido em 05/10/12. Aceito em 08/05/13. 